\title{
BioéthiqueOnline
}

\section{Multisite Research Ethics Review: Problems and Potential Solutions}

\section{Aidan Ferguson et Zubin Master}

Volume 5, 2016

URI : https://id.erudit.org/iderudit/1044265ar

DOI : https://doi.org/10.7202/1044265ar

Aller au sommaire du numéro

Éditeur(s)

BioéthiqueOnline

ISSN

1923-2799 (numérique)

Découvrir la revue

Citer cet article

Ferguson, A. \& Master, Z. (2016). Multisite Research Ethics Review: Problems and Potential Solutions. BioéthiqueOnline, 5. https://doi.org/10.7202/1044265ar
Résumé de l'article

Les essais cliniques multicentriques à grande échelle ont augmenté en fréquence. À l'heure actuelle, un projet de recherche réalisé dans plusieurs institutions nécessite une évaluation éthique pour chaque établissement. Bien que l'évaluation (institutionnelle) locale peut être nécessaire dans certains cas, les évaluations répétitives peuvent nécessiter des changements inutiles et ne servent pas à protéger davantage les participants. Il a été démontré que le fait d'avoir plusieurs évaluations éthiques d'une seule étude retarde la recherche et exige, dans certains cas, des ressources importantes afin de satisfaire aux demandes des différents comités d'éthique. Cette revue de la littérature aborde les questions conceptuelles et présente les recherches empiriques entourant l'évaluation éthique multicentrique de différentes juridictions. Elle aborde également les méthodes alternatives pour rationaliser le processus d'évaluation éthique, y compris l'évaluation réciproque et l'évaluation centralisée, ainsi qu'une proposition de modification du processus d'évaluation centralisé.
Droits d'auteur (c) A Ferguson et Z Master, 2016

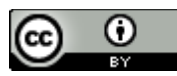

Ce document est protégé par la loi sur le droit d'auteur. L'utilisation des services d’Érudit (y compris la reproduction) est assujettie à sa politique d'utilisation que vous pouvez consulter en ligne.

https://apropos.erudit.org/fr/usagers/politique-dutilisation/ 


\section{Multisite Research Ethics Review: Problems and Potential Solutions}

ARTICLE (RÉVISION PAR LES PAIRS / PEER-REVIEWED)

Aidan Ferguson ${ }^{1}$, Zubin Master ${ }^{2}$

Reçu/Received: 28 Aug $2015 \quad$ Publié/Published: 31 Mar 2016

Éditeurs/Editors: Charles Dupras, Vanessa Chenel \& Hadi Karshoho

Évaluateurs externes/Peer-Reviewers: Renata Axler \& Anonymous

2016 A Ferguson, Z Master, Creative Commons Attribution 4.0 International License

\section{Résumé}

Les essais cliniques multicentriques à grande échelle ont augmenté en fréquence. À l'heure actuelle, un projet de recherche réalisé dans plusieurs institutions nécessite une évaluation éthique pour chaque établissement. Bien que l'évaluation (institutionnelle) locale peut être nécessaire dans certains cas, les évaluations répétitives peuvent nécessiter des changements inutiles et ne servent pas à protéger davantage les participants. II a été démontré que le fait d'avoir plusieurs évaluations éthiques d'une seule étude retarde la recherche et exige, dans certains cas, des ressources importantes afin de satisfaire aux demandes des différents comités d'éthique. Cette revue de la littérature aborde les questions conceptuelles et présente les recherches empiriques entourant l'évaluation éthique multicentrique de différentes juridictions. Elle aborde également les méthodes alternatives pour rationaliser le processus d'évaluation éthique, y compris l'évaluation réciproque et l'évaluation centralisée, ainsi qu'une proposition de modification du processus d'évaluation centralisé.

\section{Mots clés}

recherche multicentrique, recherche sur des sujets humains, comité d'éthique de la recherche, comité d'évaluation institutionnel, évaluation réciproque, évaluation centralisée, avis éthique multicentrique

\section{Abstract}

Large scale, multisite clinical research trials have been increasing in frequency. As it stands currently, a research project performed at multiple institutions requires ethics review at each institution. While local (institutional) review may be necessary in some instances, repetitive reviews may require unnecessary changes and not serve to further protect participants. Multiple ethics reviews of a single study have been shown to delay research and require, in some cases, significant resources in order to fulfill the requests of individual ethics boards. This literature review discusses the conceptual issues and outlines empirical research surrounding multisite ethics review from different jurisdictions, as well as alternative methods to streamline the ethics review process including reciprocal review, centralized review, and a proposed modification to the centralized review process.

\section{Keywords}

multisite research, human subject research, research ethics board, institutional review board, reciprocal review, centralized review, multisite ethics review

\section{Responsabilités des évaluateurs externes}

Les évaluations des examinateurs externes sont prises en considération de façon sérieuse par les éditeurs et les auteurs dans la préparation des manuscrits pour publication. Toutefois, être nommé comme examinateur n'indique pas nécessairement l'approbation de ce manuscrit. Les éditeurs de BioéthiqueOnline assument la responsabilité entière de l'acceptation finale et la publication d'un article.

\section{Peer-reviewer responsibilities}

Reviewer evaluations are given serious consideration by the editors and authors in the preparation of manuscripts for publication. Nonetheless, being named as a reviewer does not necessarily denote approval of a manuscript; the editors of BioéthiqueOnline take full responsibility for final acceptance and publication of an article. 
Affiliations des auteurs / Author Affiliations

${ }^{1}$ Virginia Commonwealth University's School of Social Work, Virginia, USA

${ }^{2}$ Alden March Bioethics Institute, Albany Medical College, New York, USA

\section{Correspondance / Correspondence}

Zubin Master, zubin@zubsplace.com

\section{Remerciements}

Nous tenons à remercier le professeur Timothy Caulfield et les deux évaluateurs externes pour leurs commentaires utiles qui servent à améliorer le manuscrit.

\section{Conflit d'intérêts}

Zubin Master est un éditeur à BioéthiqueOnline et un collaborateur de longue date avec l'éditeur en chef, Bryn Williams-Jones. Ni Master ni Williams-Jones n'étaient en aucun cas impliqué dans l'évaluation ou l'approbation du manuscrit.

\section{Acknowledgements}

We would like to thank Professor Timothy Caulfield and the two peer reviewers for their helpful feedback which served to strengthen the manuscript.

\section{Conflicts of Interest}

Zubin Master is an editor at BioéthiqueOnline and long-time collaborator with the Editor-in-Chief, Bryn Williams-Jones. Neither Master nor Williams-Jones were in anyway involved in the evaluation or approval of the manuscript.

\section{Introduction}

In many countries, ethics review of research involving humans is performed locally by ethics boards within institutions (e.g., hospitals, research centres, universities and colleges). Local review is considered important because institutional boards are knowledgeable about the type of research being conducted at their institution and the community's traditions, education, risk factors, and prevalence of certain health conditions [1,2]. Because of the close nature of the relationship between institutions and their population, local review can also serve to enhance trust in researchers and the institution. As more research involves large multicentre collaborations spanning states and countries, especially in the context of public health research, ethics review has become increasingly complex because individual ethics boards are required to independently review the same research protocol performed at their institution. Several studies have shown that local ethics review of multi-institutional or multisite research causes delays in the execution of research [3-8], drives-up research and administrative costs [7-9], decreases participant enrolment [10], delays or deters the recruitment of researchers and trainees on projects [11-12], and requires unnecessary changes including playing on the wording of consent documents making them longer and more difficult to understand and requiring minor word changes or formatting in specific documents none of which seem to further protect participants [13-14]. Several conceptual and empirical studies have begun to surface and strategies to streamline multisite review have been developed and are being implemented $[13,15]$.

In this paper, we review the academic literature, with a focus on the United States and Canada, regarding the ethical and practical considerations of multisite ethics review and discuss the implementation of alternative review processes: reciprocal and centralized review. We report that processes to consolidate review have several advantages while recognizing that in some cases, individual review is still necessary. We conclude that both reciprocal and centralized review processes have advantages and disadvantages for different reasons and that further research measuring the effectiveness of multisite review is needed. With more knowledge on the efficacy of multisite ethics review processes, government and non-government organizations can give more explicit directions on how individual research ethics boards can participate in multisite processes.

\section{The Status Quo: Research Ethics Review by Local Boards}

The ethical review of publicly funded research involving humans is performed within nations, usually through a mixture of federal and state/provincial policies. In both the U.S. and Canada, ethical review of research is governed federally. In the U.S., ethics review of human research is governed through federal regulations known as the Common Rule, which list provisions for board membership, informed consent, and compliance by participating institutions [16]. Research ethics in Canada is governed by 
federal guidelines from the three federal funding agencies: Natural Sciences and Engineering Research Council of Canada, Social Sciences and Humanities Research Council, and the Canadian Institutes of Health Research in a policy known as the Tri-Council Policy Statement: Ethical Conduct of Research Involving Humans, $2^{\text {nd }}$ edition (TCPS2) [17]. In these countries and others, ethics review is performed by local boards or committees: Institutional Review Boards (IRBs) in the U.S., Research Ethics Boards (REBs) in Canada, and Research Ethics Committees (RECs) in the United Kingdom, for instance. The main purpose of ethics review is to ensure that research is performed according to certain ethical norms and standards in order to protect research participants [4-5,18]. While a thorough review of the norms and practices governing research ethics is beyond the scope of this paper, ethics boards generally assess several scientific and ethical aspects of research including scientific value and validity, subject recruitment, risk-benefit analysis, informed consent, participant withdrawal, privacy, adverse events monitoring and reporting, reporting of results and/or incidental findings to participants, management of conflicts of interest, and adherence to international, federal and state/provincial policies [19-22]. Ethics boards review a range of research including drug trials, psychiatric studies, social science and psychology research, drug-based research, and surgical studies among others [23-24]. Depending on the magnitude and type of research conducted within the organization, institutions may have a general ethics board that reviews all research involving humans or may have specialized boards that focus on particular areas of research (e.g., behavioural versus clinical research).

Multisite research has become an increasingly common way to conduct research, as seen by an 8 to 9-fold increase between 1985 and 1999 in large cohort epidemiology studies [25]. Multisite studies tend to recruit large numbers of heterogeneous or specific populations from different geographical areas $[2,6,8,10,13,26-28]$. In particular, phase 3 and 4 clinical trials may require the recruitment of hundreds of participants and often cover a large geographic area to increase generalizability. Such studies require the concerted effort of many investigators at multiple institutions to recruit participants, administer procedures, and collect data.

Several studies have examined the conduct of ethics review at multiple institutions using a range of methods, including the review of ethics boards' outcomes and perceptions of board members [1,6,11,29-30] and researchers [4,31], examination of documents/records [32], and descriptive review/analysis of individual board review and approval processes [12,33]. These studies have outlined a range of issues in local ethics review of multisite research including variation in informed consent $[5-6,12,26]$, risk-benefit analysis [5,8,30,32,34], differences in board members' understanding of legislative and regulatory requirements [3,12,34], difficulty or confusion regarding privacy compliance $[4,26,32]$, differences in when to exempt research $[5,13,32]$, delays in the commencement and/or dissemination of research [1,3-6,8], and delays in the recruitment of participants [10]. Researchers also report frustration with many aspects of multisite ethics review, including delays, the increased time, effort and cost to address changes, lack of cooperation between ethics boards, and the lack of standardization in ethics review [4,31,35]. Unfortunately, the research community is experiencing major issues with the way ethics boards respond to multisite research protocols that may negatively impact researchers, potential and current research participants, and the public [2,8,36-38]. We need to be mindful, however, that inconsistencies in research ethics review across local boards does not always imply a reduction in the quality of review. In some cases, repetition in review might lead to greater scrutiny of the protocol and increase the quality of reviews. At the same time, inconsistencies in ethics review can be administratively burdensome, not only for the ethics boards, but also for researchers and it could lead to potential harms to research participants.

\section{Inconsistencies in Ethics Review and Potential Harms to Participants}

While inconsistencies in multisite review by local boards may not continually undermine the thoroughness or quality of reviews, in some instances it could undercut certain protections offered to participants. This can be seen with boards having varying expectations of the language used in 
informed consent documents, and how boards consider issues of risk, privacy, and equitable participant selection.

Due to the emphasis that ethics board members place on informed consent, it is not surprising that there are significant variations among them on this issue. For example, in the U.S., IRB-approved protocols may include variation in consent requirements, and requested changes have been shown to reduce the understanding of informed consent documents [39]. Silverman and colleagues [40] analyzed informed consent documents of 16 IRBs participating in a multicentre trial and found that IRBs varied in their requirements regarding the description of risks, benefits, alternate treatment options, maintaining confidentiality, and informing patients that they are participating in research and their participation is voluntary. Interestingly, 6 of 16 consent forms approved by IRBs failed to contain any of the above elements and 9 provided incomplete information to participants about the alternatives to participation. Another study showed that local review boards of 25 different sites made a median of 46.5 changes to the consent form causing errors in two thirds of the forms and creating forms that were longer and more difficult to read [2].

Beyond the variations in informed consent described above, equitable participant selection, protection of vulnerable populations, and privacy and confidentiality measures may also change from one ethics board to another. One study found that IRBs failed to adequately compare risks and benefits $21 \%$ of the time, equitable subject selection $60 \%$ of the time, and privacy and confidentiality $12 \%$ of the time [23]. Some ethics boards might approve a study as minimal risk with waiver of consent while others outright rejected the application, requiring more information [12]. In one instance, an IRB requested that copies of consent forms be kept in an administrative office of the participants' employer, instead of the researcher's office, which may have impinged on participant privacy and negatively affected their employment [12].

Multiple studies point out that variation in research protocol, informed consent, administration, privacy protections, and determining appropriate levels of risk can create, at a minimum, uneven human protections that undermine the Common Rule [5,8-9,25,41-44]. Researchers warn that when the "public hears about problems," people could determine that "research might be unsafe and existing protections ineffective," thereby reducing the public's trust and participation in research [41].

Despite the aforementioned studies showing variation among research ethics review, there are cases where independent board reviews are necessary. For example, medical research conducted in rural towns or communities may have participant populations with a reading level lower than the national standard of about a grade 8 level. Here, an ethics board may require that informed consent be brought down to a reading level suitable for the community to be best informed about a study prior to their enrollment. There might also be cases where a large, culturally unique population resides and has different values and views on informed consent. This is well recognized of many aboriginal communities where there may be a different approach to performing research and obtaining consent. Canada has drafted specific provisions, initially as separate guidelines and now part of the TCPS2, for research involving aboriginal peoples [17]. Along with cases where local ethics review is required, it is important to recognize that inconsistencies in the review of research protocols by local boards does not necessarily equate, in all cases, with direct or indirect harm to participants.

\section{Delays in Conducting and Disseminating Research During Local Ethics Review of Multisite Studies}

In addition to inconsistent reviews, another major concern reported in the academic literature regarding multisite ethics review are delays in conducting and disseminating research due to additional requests by boards for minor and likely unnecessary changes [14,32,35]. Several studies show that submission-to-approval times range from as few as 5 days and up to 252 days [14,32]. Sarson-Lawrence [14] noted that $30 \%$ of changes requested by local boards were nothing more than 
"minor errors" such as word changes. In one example, researchers submitted 105,888 pages of application materials to 125 ethics boards with an estimated cost of $\$ 10,286.83$ for paper, photocopying and postage for a single study, demonstrating staggering administrative costs [8]. Not surprisingly, researchers involved in multisite studies report the process frustrating and unnecessarily burdensome [15,31]. Delays in ethics board decisions may postpone recruitment [45] and will likely lead to concomitant delays in the public reporting of research, ultimately postponing the transition of medicines and diagnostics to the marketplace [36].

While regulations, guidelines, and accreditation offer guidance in research ethics review, they are not overly prescriptive regarding consensus in the interpretation of research ethics practices. As differences in individual board members' interpretation of specific research protections exist, the variation seen internally among board members and between different boards seems inescapable. To reduce variation, several alternate models to ethics review of multisite research have been proposed and implemented. In the examples below, we illustrate two common features that aim to reduce the variation in the interpretation and implementation of research ethics review practices. The first aims to reduce the number of separate reviews and the second involves agreeing on common practices and procedures.

\section{Alternate Models of Ethics Review of Multisite Studies}

While local review has several advantages (e.g., knowing the study population), in some cases, it is unclear whether local review is the most effective method for large, multicentre trials. Alternate methods of multisite review might offer an opportunity to save time, energy, and resources, as well as increase participant protections. To circumvent the issues outlined above, two common alternative models for multicentre research ethics review have been suggested and implemented: reciprocal review and centralized review (see Table 1). 
Table 1: Institutions Implementing Reciprocal and Centralized Review Processes

\begin{tabular}{|c|c|c|}
\hline Example & Description & Reference \\
\hline \multicolumn{3}{|l|}{ Reciprocal Review } \\
\hline $\begin{array}{l}\text { Harvard Catalyst } \\
\text { Institutions }\end{array}$ & $\begin{array}{l}\text { Consists of } 9 \text { institutions in the Boston area engaged in a reciprocal common IRB } \\
\text { reliance agreement allowing a participating site to agree to use one IRB's review for } \\
\text { new submissions or amendments to the protocol for all participating institutions on a } \\
\text { case-by-case basis. Winkler, Witte, \& Bierer [47] noted that the Harvard Catalyst } \\
\text { system of reciprocal review may reduce burden and inconsistencies inherent to single } \\
\text { site review which may result in increased cooperation, trust and communication among } \\
\text { institutions. Located in the U.S. with multi-clinical focus. https://catalyst.harvard.edu/ }\end{array}$ & 46,47 \\
\hline Cancer Trials Australia & $\begin{array}{l}\text { Studied the use of a model of mutual acceptance where several National Health and } \\
\text { Medical Research Councils agreed to accept the reviews of a primary Human } \\
\text { Research Ethics Committee. Concluded that this model resulted in a } 27 \% \text { reduction in } \\
\text { approval time and stakeholders professed a high level of approval in the system, } \\
\text { although each site needed to complete a separate legal review following the ethical } \\
\text { review by the primary ethics committee, which could delay the commencement of } \\
\text { research. Cancer Trials Australia is a clinical trial network for oncology trials of single } \\
\text { and multisite research projects that currently has } 19 \text { member institutions. Located in } \\
\text { Australia, with a focus on cancer research. https://www.cancertrialsaustralia.com/ }\end{array}$ & 48 \\
\hline \multicolumn{3}{|l|}{ Centralized Review } \\
\hline $\begin{array}{l}\text { Ontario Cancer } \\
\text { Research Ethics } \\
\text { Board (OCREB) }\end{array}$ & $\begin{array}{l}\text { In 2003-2004, OCREB began reviewing multicentre oncology trials in Ontario and } \\
\text { currently serves as the board of record for } 26 \text { of } 27 \text { hospital centres. The board is } \\
\text { composed of medical/scientific experts, ethicists, researchers, healthcare providers, } \\
\text { legal experts and community members. In a } 2014 \text { annual report, it was noted that the } \\
\text { board reviewed approximately } 70 \text { new studies a year with an average approval taking } \\
\text { only } 56 \text { days. The study also noted that } 94 \% \text { and } 77 \% \text { of stakeholders rated the review } \\
\text { services by this board as good or excellent, respectively. Located in Ontario, Canada, } \\
\text { with a focus on cancer research. http://oicr.on.ca/oicr-programs-and-platforms/ontario- } \\
\text { cancer-research-ethics-board }\end{array}$ & $49-51$ \\
\hline $\begin{array}{l}\text { National Cancer } \\
\text { Institute Central IRB }\end{array}$ & $\begin{array}{l}\text { This central IRB has } 265 \text { adult and } 128 \text { pediatric institutions that participate in a } \\
\text { centralized review process where one review is completed by a central IRB for each } \\
\text { proposal, as well as a facilitated review by the independent IRBs to address local } \\
\text { issues. The central board is composed of scientific and non-scientific oncology } \\
\text { experts, such as nurses, providers, patient representatives and statisticians. A study } \\
\text { found the benefits of this review process to be more predictable, faster and cost- } \\
\text { effective on the initial review, but the savings accrued did not exceed the cost of } \\
\text { running the centralized IRB ( } \$ 55,000 \text { a month). Located in the U.S, with a focus on } \\
\text { cancer research. https://ncicirb.org/cirb/default.action }\end{array}$ & 50,52 \\
\hline $\begin{array}{l}\text { Multi-Centre Research } \\
\text { Ethics Committee } \\
\text { (MREC) }\end{array}$ & $\begin{array}{l}\text { Until 2004, some research institutions in the United Kingdom used a national review } \\
\text { board, made up of several regional multi-centre research ethics committees, known as } \\
\text { the MREC. After review by the MREC, the same study protocol would be reviewed by } \\
\text { the local REC in an attempt to expedite the review process for multicenter research. } \\
\text { Unfortunately, the consolidated review process was met with considerable criticism } \\
\text { from the research community who felt that centralization increased rather than } \\
\text { decreased the inefficiencies in the review process. Located in the United Kingdom. }\end{array}$ & 51 \\
\hline $\begin{array}{l}\text { University of } \\
\text { Alberta/Capital Health } \\
\text { Region/Caritas } \\
\text { Hospitals Group }\end{array}$ & $\begin{array}{l}\text { The Health Research Ethics Board is contractually the review board of record for } \\
\text { clinical research conducted within the University of Alberta, Capital Health Region and } \\
\text { Caritas Hospitals Group. Located in the province of Alberta, Canada. }\end{array}$ & 51 \\
\hline $\begin{array}{l}\text { McGill University's } \\
\text { Faculty of Medicine }\end{array}$ & $\begin{array}{l}\text { McGill University's Faculty of Medicine uses affiliation agreements with other } \\
\text { participating institutions to facilitate a centralized review process within their } \\
\text { participating sites. It was noted that these partnerships provided not only enhanced } \\
\text { protections for participants, but work on the basis of trust between the institutions, } \\
\text { negating the need for local review of proposals. This review board reviews clinical } \\
\text { research. Located in the province of Quebec, Canada. }\end{array}$ & 51 \\
\hline $\begin{array}{l}\text { Harmonization of } \\
\text { Multi-centre Ethical } \\
\text { Review }\end{array}$ & $\begin{array}{l}\text { In 2006, the Australian Health Ministry Advisory Council sought to implement a } \\
\text { national system of centralized review entitled Harmonization of Multi-centre Ethical } \\
\text { Review (HoMER), although local approval must still be gained following the centralized } \\
\text { review approval. }\end{array}$ & 53 \\
\hline
\end{tabular}




\section{Reciprocal Review}

Reciprocal review entails an arrangement between two or more ethics boards at different institutions who agree to accept the ethics review conducted by another board [15]. Establishing a reciprocal arrangement usually requires participating boards to develop a trusting relationship, a common means of assessing protocols, a common set of forms and templates provided to researchers, and may include having similar standard operating procedures. To operationalize reciprocal review, individual ethics boards need to reach a common agreement on concerns about liability, timeliness of reporting adverse events, approaches to review, and the considerations of taking corrective actions on protocols when in violation of research ethics policy. These challenges are not to be taken lightly as the process of setting up reciprocal arrangements takes a significant amount of time of the boards' chairs, members and administrative staff, and other university staff (e.g., Vice-President Research, legal services). The process of establishing reciprocal agreements is likely to be a costly endeavor due to the initial time and resource investment, which might deter boards from initiating reciprocal agreements as they simply do not have the time and resources.

Several institutions have implemented reciprocal review processes with some indication of success (Table 1). Cancer Trials Australia resulted in reduced review time, but the arrangement required an initial investment by institutions, researchers and review boards [48]. Some boards may be reluctant to defer their review power to another authority, and may experience trepidation due to a misunderstanding of the process. Reciprocal review can be a viable option for local boards to consider, but additional research is needed regarding their establishment and efficiency.

\section{Centralized Review}

Centralized review is when several research institutions enter into an agreement to allow one board to conduct ethics reviews on behalf of all the participating sites; the board reviewing the protocol becomes an official board of record. Centralized review boards may consist of individuals with specific expertise in a particular subject area, such as cancer research, and this may serve for a more thorough ethics review, enhance participant protection, and better distribute workload $[10,15,18,28,51,54]$. In some circumstances, centralized review does not completely eliminate individual boards from conducting an administrative review to determine whether to accept the board of record's review.

Boards in many states/provinces and countries have in place, or are in the process of establishing, centralized review systems (Table 1). Centralized review can reduce costs by ensuring less duplication of paperwork, reduced variability, and fewer delays in participant enrolment and the commencement of research [27], as well as ensure that unexpected and adverse events are quickly identified and reported so corrective action can be taken [18]. Centralized review can reduce the burden on investigators, increase consistency in the protection of research participants, and ensure quick dissemination of any change in protocol to participating institutions [11,18,55-57]. One novel suggestion from the U.S. is to conduct centralized review virtually; overseen by U.S. Office of Human Research Protections, this would allow reviewers to remain at their institutions but provide "unprecedented" expert review specific to the research at hand, as well as real time information regarding adverse events and monitoring [43,58]. Other authors suggest something similar, using a "web-based cooperative IRB review" that would enable reviewers from other geographic areas to interact [59]. Another suggestion, by Mann and Shamoo [57], is the establishment of a system of centralized regional ethics organizations that could promote the involvement of the research ethics community as a way to improve oversight for industry sponsored research.

However, concerns have been raised about centralized review: 1) legal concerns of one board accepting the review of another; 2) centralized boards might not understand the culture of participating ethics boards/institutions and the needs of the local population; and 3) centralized boards might not be able to communicate effectively with local investigators $[15,29,48,55,58]$. Autonomy and 
independence of boards continues to be touted as desirable in order to understand communityspecific needs resulting in a preference towards local control [1]. Due to uneasiness over accepting another ethics boards' decision, and confusion over how ethics and human protections issues are handled through an outside board, researchers and research institutions have concerns that local boards may not have the motivation and lack experience in participating in a centralized review process [60]. In spite of these concerns, several organizations - including the U.S. Department of Agriculture and the Department of Health and Human Services - have demonstrated support for using a centralized approach [60]. Centralized review, while having some drawbacks, does seem to provide a reduction in workload, faster review times, and better distribution of changes to the protocol.

While both reciprocal and centralized review has their place, in some cases, multisite review mechanisms might be less appropriate and local review would be necessary. One example would be the need for a catholic hospital to review all protocols to ensure that research on abortion or using aborted fetuses would not be permitted. A second example that may limit multisite review mechanisms from being established is based on differences in jurisdictional policies. For example, privacy policies from different provinces in Canada may differ in the safeguards that need to be in place. The heterogeneity in national and state/provincial policies might limit such multisite ethics review processes from being practiced in geographically dispersed areas.

\section{Current Guidance to Ethics Boards on Multisite Ethics Review}

As research expands from single site into multisite research, governing bodies have had to address the ethical conduct of research in these new settings. In Canada, the TCPS2 [17] now has a specific chapter devoted to multi-jurisdictional research in an effort to ensure that the same ethical considerations and procedures used in reviewing single site research are not overlooked in multisite review. The TCPS2 places the responsibility of ensuring ethical conduct of research and the decision of whether to use traditional or alternate review processes on institutional REBs, and offers little in terms of guidance on how alternate review practices could be implemented [17]. The U.S. Department of Health and Human Services regulations provide a statement allowing IRBs to enter into a "joint review arrangement" [61]. Similarly, the Common Rule explains that multisite studies may benefit from minimizing burden and increasing effectiveness, but provides little guidance on how to establish such practices [62]. In 2011, the Department of Health and Human Services issued an advance notice of proposed rulemaking (ANPRM) [61] soliciting comments for updating several regulations, including the streamlining of IRB review for multiple sites through the designation of one IRB of record. The ANPRM points out that the Common Rule requires researchers to obtain IRB approval, but does not require that this approval come from each local board participating in the research project.

In September 2015, a Notice of Proposed Rulemaking (NPRM) [63] was released, following the ANPRM in 2011, for comment on proposed changes to the Common Rule, including a recommendation for a centralized review process to be used in multisite research. Proposed changes included a mandate for institutions to use an IRB of record for multisite research instead of reliance on individual review by local review boards. The NPRM also recommends that the review board of record be given the ability to enforce compliance on unaffiliated/non-conforming review boards and be held liable for flawed review instead of local review boards. The expectation is that the proposed changes will dispel unease with individual review boards ceding control to another board, promote collaboration between review boards, and remove arduous review processes [63]. However, the proposed changes do not address how to hold unaffiliated review boards accountable nor how individual review boards can go about selecting a review board of record considering that the latter will be responsible for any liability. Because these recommendations are not fully explained, it may be difficult to convince individual review boards to use a centralized review process based on these proposed changes. While it appears that many major national policies are starting to recognize the need for multisite review through the introduction of some guidance in policy statements, review boards may continue to be reluctant to institute alternate review strategies without increased support and guidance. 


\section{Limitations}

While this literature review considers international studies of multisite research ethics review (though primarily from the U.S. and Canada), it is important to note the context under which these studies were conducted, such as jurisdiction of review, national, state/provincial policies, and the type of study (behavioural vs. clinical). The literature review also focuses on publicly funded research using academic review boards; privately/sponsored research and private boards may have different experiences.

\section{Conclusion}

Our analysis of the literature on multisite ethics review suggests that local review boards can offer advantages of improved understanding of local community needs and traditions. This may, however, result in inconsistency in review requiring unnecessary changes that can drive-up costs and delay research. While alternate review processes may better control inconsistencies in the review process, they will not necessarily lead to a better quality of review in all cases. Some local review boards have shown resistance to reforming the review process for multisite studies, but this resistance may be due to unsubstantiated perceptions of legal liability and accountability, and the desire to understand local needs. Because adoption of multisite review practices take a substantial amount of time, energy, knowledge and financial resources, local boards may be reluctant to begin changing practices.

Centralized and reciprocal review processes have several advantages. Centralized review boards have been shown to better address ethics reviews in a specialized area of research, e.g., cancer research, whereas boards engaged in reciprocal review may be more efficient at uniting individual boards in a certain geographical area. One issue that might prevent reciprocal arrangements or boards engaging in centralized review processes is that of trust. Having a committee of experts in cancer research with ethics board members concentrating only in a specialized area may result in enhancing trust in the centralized board and the review process. Similarly, boards in a certain geographical area, which know their patient population, might also begin undertaking the development of common forms and templates and gradually build trust in the process of developing a reciprocal agreement. Both centralized and reciprocal review thus have their place in ensuring robust ethics review while striving for greater efficiency in the process.

We propose a modification of centralized ethics review that aims to streamline the ethics review process by having a single board of record, but by also having non-voting representatives of individual boards. This might help address concerns of trust and ensure that due diligence by the central board meets the standards of individual boards. Concerns can be voiced and brought up, but individual board representatives cannot vote in order to ensure timely ethics review. Having a venue for local boards to express concerns present in their local community is likely a feature they would deem important and offer them the satisfaction that their voices can be heard. If representatives believe that the reviews being conducted are not up to their standards, they can relay this back to their board chairs and members and make a decision on whether to continue participating. By having a representative on the central board, representatives can witness the integrity and quality of the review process, communicate concerns, and relay issues back to their individual board. Individual representatives may participate by attending meetings or attend meetings via video or teleconference when their protocol is being reviewed. While this modification may reduce localized issues, one limitation is that there can only be a limited number of individual board representatives who can attend. The centralized board can develop procedures to have board representatives periodically attend meetings, initially when the individual board joins the centralized process, and when there is a particularly contentious or problematic research project being reviewed. A second limitation to this process is that overall, the process may take slightly more time due to the need to call in individual board representatives when protocols are being reviewed and a greater degree of organization would 
be needed by the centralized board of record to manage protocols by different boards and to consolidate review.

Although greater guidance on multisite ethics review is given, most notably in the NPRM in the U.S., there remains little detailed direction on several of the salient issues that individual boards need to address prior to any reform, e.g., time, financial resources, trust, and perceptions of accountability and liability. We argue that greater policy direction is needed as independent boards are likely aware of these issues, but may not have the means and knowledge to undertake reforms. Collaboration between national and local levels in policy/regulation development might provide more ease with implementation, while national agencies overseeing ethics review, or other non-government bodies or groups interested in research ethics, could make efforts to educate Chairs, leaders and members of independent boards. This could be done through education efforts such as specialized workshops or conferences where legal, policy and logistic issues are discussed in greater detail to help independent boards gain the necessary knowledge to begin the process of joining or creating a multisite ethics review process. While this may not circumvent resource issues, universities, colleges and hospitals/research centres must invest further in their independent boards in order to actualize a process of multisite ethics review.

As a more reciprocal and centralized review strategies are implemented, further research is also needed on these initiatives, not only in terms of how efficiently multisite review is performed, but also the steps and hurdles that local boards encounter during the development of uniform review policies and practices. While there are certainly instances where local review may be necessary, in many cases stakeholders in research practice and governance may benefit from more streamlined and collaborative processes.

\section{References}

1. Klitzman $\mathrm{R}$. The myth of community differences as the cause of variations among IRBs. AJOB Primary Research 2011; 2(2): 24-33.

2. Burman W, Breese $P$, Weis $S$., et al. The effects of local review on informed consent documents from a multicenter clinical trials consortium. Controlled Clinical Trials 2003; 24(3): 245-255.

3. Dyrbye LN, Thomas MR, Mechaber AJ, et al. Medical education research and IRB review: an analysis and comparison of the IRB review process at six institutions. Academic Medicine 2007; 82(7): 654-660.

4. Ezzat $H$, Ross $S$, von Dadelszen $P$, et al. Ethics review as a component of institutional approval for a multicentre continuous quality improvement project: the investigator's perspective. BMC Health Services Research 2010; 10(1): 223.

5. Larson E, Bratts T, Zwanziger J, et al. A survey of IRB process in 68 US hospitals. Journal of Nursing Scholarship 2004; 36(3): 260-264.

6. Driscoll A, Currey J, Worrall-Carter L, Stewart S. Ethical dilemmas of a large national multicentre study in Australia: time for some consistency. Journal of Clinical Nursing 2008; 17(16): 2212-2220.

7. Salman RAS, Brock TM, Dennis MS, et al. Research governance impediments to clinical trials: a retrospective survey. Journal of the Royal Society of Medicine 2007; 100(2): 101-104.

8. Gold JL, Dewa CS. Institutional review boards and multisite studies in health services research: is there a better way? Health Services Research 2005; 40(1): 291-308.

9. Willison DJ, Emerson C, Szala-Meneok, et al. Access to medical records for research purposes: varying perceptions across research ethics boards. Journal of Medical Ethics 2008; 34(4): 308-314.

10. Peterson LA, Simpson K, SoRelle R, et al. How variability in the institution review board review process affects minimal-risk multisite health services research. Annals of Internal Medicine 2012; 156(10): 728-735. 
11. Mansbach J, Acholonu U, Clark S, et al. Variation in institutional review board responses to a standard, observational, pediatric research protocol. Academic Emergency Medicine 2007; 14(4): 377-380.

12. Green LA, Lower JC, Kowalski CP, Wyszewianski L. Impact of institutional review board practice variation on observational health services research. Health Services Research 2006; 41(1): 214-230.

13. Greene SM, Geiger AM. A review finds that multicenter studies face substantial challenges but strategies exist to achieve Institutional Review Board approval. Journal of Clinical Epidemiology 2006; 59(8): 784-790.

14. Sarson-Lawrence M, Alt C, Mok MT, et al. Trust and confidence: towards mutual acceptance of ethics committee approval of multicentre studies. Internal Medicine Journal 2004; 34(11): 598-603.

15. Abbott J, Bergeron M, Hoddinott S, et al. Ethics review of research involving multiple setting and/or involving multiple REBs (previously multicentered ethics review): a discussion paper and recommendations. Subgroup on Procedural Issues for the TCPS (ProGroup): A Working Committee of the Interagency Advisory Panel on Research Ethics (PRE); 2008.

16. U.S. Department of Health and Human Services. Code of Federal Regulations: Title 45 Public Welfare: Part 46 Protection Of Human Subjects (45 CFR 46); 2009.

17. Panel on Research Ethics. Tri-Council Policy Statement: Ethical Conduct for Research Involving Humans, second edition (TCPS2); 2014.

18. Emanuel EJ, Wood A, Fleischman A, et al. Oversight of human participants research: identifying problems to evaluate reform proposals. Annals of Internal Medicine 2004; 141(4): 282-291.

19. Smith E, Master Z. Ethical practice of research involving humans. Reference Module in Biomedical Research 3rd Edition. Oxford: Elsevier; 2014

20. Vick CC, Finan KR, Kiefe C, et al. Variation in Institutional Review processes for a multisite observational study. The American Journal of Surgery 2005; 190(5): 805-809.

21. Sieber JE. Ethical considerations in planning and conducting research on human subjects. Academic Medicine 1993; 68(9): S9-13.

22. Sullivan GM. Education research and human subject protection: crossing the IRB quagmire. Journal of Graduate Medical Education 2011; 3(1): 1-4.

23. Lidz CW, Appelbaum PS, Arnold R, et al. How closely do institutional review boards follow the Common Rule? Academic Medicine 2012; 87(7): 969-974.

24. Saleem T, Khalid U. Institutional review boards - a mixed blessing. International Archives of Medicine 2011, 4:19.

25. McWilliams R, Hoover-Fong J, Hamosh A, et al. Problematic variation in local institutional review of a multicenter genetic epidemiology study. JAMA 2003; 290(3): 360-366.

26. Sherwood ML, Buchinsky FJ, Quigley MR, et al. Unique challenges of obtaining regulatory approval for a multicenter protocol to study the genetics of RRP and suggested remedies. Otolaryngology - Head and Neck Surgery 2006; 135(2): 189-196.

27. Hammatt ZH, Nishitani J, Heslin KC, et al. Partnering to harmonize IRBs for communityengaged research to reduce health disparities. Journal of Health Care for the Poor and Underserved 2011; 22(4 Suppl): 8-15.

28. Wadman M. Proposed centralization of trial oversight stirs mixed reaction. Nature Medicine 2011; 17(9): 1025.

29. Helfand BT, Mongiu AK, Roehrborn CG, et al. Variation in institutional review board responses to a standard protocol for a multicenter randomized, controlled surgical trial. The Journal of Urology 2009; 181(6): 2674-2679.

30. Shah S, Whittle A, Wilfond B, et al. How do institutional review boards apply the federal risk and benefit standards for pediatric research? JAMA 2004; 291(4): 476-482.

31. Master Z, Ries NM, Caulfield T. Balancing efficiency and the protection of research participants: Canadian Allergy/Asthma Researchers' perspectives on the ethics review of multi-site health research. Journal of Clinical Research Bioethics 2011; 2(5): 104e. 
32. Dziak K, Anderson R, Sevick MA, et al. Variations among Institutional Review Board reviews in a multisite health services research study. Health Services Research 2005; 40(1): 279-290.

33. Hirshon JM, Krugman SD, Witting MD, et al. Variability in Institutional Review Board Assessment of Minimal-risk Research. Academic Emergency Medicine 2002; 9(12): 14171420.

34. Blustein J, Regenstein M, Siegel B, Billings J. Notes from the field: jumpstarting the IRB approval process in multicenter studies. Health Services Research 2007; 42(4): 1773-1782.

35. Abramovici, A, Salazar A, Edvalson, T, et al. Review of multicenter studies by multiple institutional review boards: characteristics and outcomes for perinatal studies implemented by a multicenter network. American Journal of Obstetrics 2015; 212(1): 110.e1-110.e6.

36. Millium J, Menikoff J. Streamlining ethical review. Annals of Internal Medicine 2010; 153(10): 655-657.

37. Studdert DM, Vu TM, Fox SS, et al. Ethics review of multisite studies: the difficult case of community-based Indigenous health research. Medical Journal of Australia 2010; 192(5): 275280.

38. Legro RS. Barriers to conducting clinical research in reproductive medicine: United States of America. Fertility and Sterility 2011; 96(4): 817-819.

39. Candilis, PJ, Lidz CW, Arnold RM. (2006). The need to understand IRB deliberations. IRB: Ethics \& Human Research 2006; 28(1): 1-5.

40. Silverman H, Hull SC, Sugarman J. Variability among institutional review boards' decisions within the context of a multicenter trial. Critical Care Medicine 2001; 29(2): 235-241.

41. Abbott L, Grady C. A systematic review of the empirical literature evaluating IRBs: what we know and what we still need to learn. Journal of Empirical Research on Human Research Ethics 2011; 6(1): 3-19.

42. Boult M, Fitzpatrick K, Maddern G. A guide to multi-centre ethics for surgical research in Australia and New Zealand. ANZ Journal of Surgery 2011; 81(3): 132-136.

43. Salvulescu J. Harm, ethics committees and the gene therapy death. Journal of Medical Ethics $2001 ; 27(3):$ 148-150.

44. McWilliams R, Hebden CW, Gilpin AMK. Concept paper: a virtual centralized IRB system. Accountability in Research 2006; 13(1): 25-45.

45. Finch SA, Barkin SL, Wasserman RC. Effects of local institutional review board review on participation in national practice-based research network studies. Archives of Pediatrics \& Adolescent Medicine 2009; 163(12): 1130-1134.

46. Harvard Catalyst. Regulatory Foundations, Ethics and Law Program: Master Reciprocal Common IRB Reliance Agreement. (n.d.).

47. Winkler SJ, Witte E, Bierer BE. The Harvard catalyst common reciprocal IRB reliance agreement: an innovative approach to multisite IRB review and oversight. Clinical and Translational Science, 2015; 8(1): 57-66.

48. Rosenthal MA, Sarson-Lawrence M, Alt C, et al. Ethics committee reviews and mutual acceptance: a pilot study. Internal Medicine Journal 2005; 35(11): 650-654.

49. Ontario Cancer Research Ethics Board. Annual report 2013-2014; 2014.

50. Saginur R, Dent SF, Schwartz L, et al. Ontario Cancer Research Ethics Board: lessons learned from developing a multicenter regional institutional review board. Journal of Clinical Oncology 2008; 26(9): 1479-1482.

51. Enzle ME, Schmaltz R. Ethics review of multi-centre clinical trials in Canada. Health Law Review 2005; 13(2-3): 51-7.

52. Wagner TH, Murray $\mathrm{C}$, Goldberg J, et al. Costs and benefits of the national cancer institute central institutional review board. Journal of Clinical Oncology 2010; 28(4): 662-666.

53. Prosser B, Davey R, Gibson D. Progress in centralised ethics review processes: implications for multi-study health evaluations. Evaluation and Program Planning, 2015; 49: 117-123.

54. Fitzgerald MH, Phillips PA. Centralized and non-centralized ethics review: a five nation study. Accountability in Research 2006; 13(1): 47-74. 
55. Resnik DB. Centralized institutional review boards: Assessing the arguments and evidence. Journal of Clinical Research Best Practices 2012; 8(11): 1-13.

56. Ravina B, Deuel L, Siderowf A, Dorsey ER. Local IRB review of a multicenter trial: local costs without local context. Annals of Neurology 2010; 67(2): 258-260.

57. Mann H, Shamoo AE. Introduction to special issue of accountability in research on the review and approval of biomedical research proposals: a call for a centralized national human research protections system. Accountability in Research 2006; 13(1): 1-9.

58. Caulfield T, Ries N, Barr G. Variation in ethics review of multi-site research initiatives. Amsterdam Law Forum 2011; 3: 85-100.

59. Nowak KS, Bankert EA, Nelson RM. Reforming the oversight of multi-site clinical research: a review of two possible solutions. Accountability in Research, 2006; 13(1): 11-24.

60. Flynn KE, Hahn CL, Kramer JM, et al. Using central IRBs for multicenter clinical trials in the United States. PloS one 2013; 8(1): e54999. doi: 10.1371/journal.pone.0054999.

61. Department of Health and Human Services. Human Subjects Research Protections: Enhancing Protections for Research Subjects and Reducing Burden, Delay, and Ambiguity for Investigators. Federal Register 2011; 76 FR 44512: 44512-44531

62. Emanuel EJ, Menikoff J. Reforming the regulations governing research with human subjects. New England Journal of Medicine 2011; 365(12): 1145-1150.

63. Department of Health and Human Services. Notice of Proposed Rulemaking for Revisions of the Common Rule. Federal Register, 2015; 80 FR 53931: 53931-54061. 